\title{
WestVirginiaUniversity
}

THE RESEARCH REPOSITORY @ WVU

Graduate Theses, Dissertations, and Problem Reports

2006

\section{The vessel and the sacred}

\author{
Myra Kaha \\ West Virginia University
}

Follow this and additional works at: https://researchrepository.wvu.edu/etd

\section{Recommended Citation}

Kaha, Myra, "The vessel and the sacred" (2006). Graduate Theses, Dissertations, and Problem Reports. 3247.

https://researchrepository.wvu.edu/etd/3247

This Thesis is protected by copyright and/or related rights. It has been brought to you by the The Research Repository @ WVU with permission from the rights-holder(s). You are free to use this Thesis in any way that is permitted by the copyright and related rights legislation that applies to your use. For other uses you must obtain permission from the rights-holder(s) directly, unless additional rights are indicated by a Creative Commons license in the record and/ or on the work itself. This Thesis has been accepted for inclusion in WVU Graduate Theses, Dissertations, and Problem Reports collection by an authorized administrator of The Research Repository @ WVU. For more information, please contact researchrepository@mail.wvu.edu. 
The Vessel and the Sacred

$$
\text { Myra Kaha }
$$

Thesis submitted to the

College of Creative Arts

At West Virginia University

In partial fulfillment of the requirements

For the Degree

Master of Fine Arts

In

Ceramics

\author{
Robert Anderson, Chair \\ Shaila Christofferson
}

Eve Faulkes

Division of Art

Morgantown, West Virginia

2006

Keywords: Ceramic Sculpture, Architecture, Sacred, Venus, Vessel, House 


\title{
ABSTRACT \\ The Vessel and the Sacred
}

\author{
Myra Kaha
}

Through the use of architecture as a container or vessel, the ideas of the human body, the domestic and the sacred are addressed. Architecture becomes a metaphor for the human body. Both function as a vessel. The subjects of containment and preservation are approached through the creation of vessels that store containers. 


\section{DEDICATION}

I would like to dedicate this thesis to my parents, who taught me to explore the abstract and the concrete.

Catherine Kaha Phelan

Arthur Lyon Kaha Jr. 


\section{ACKNOWLEDGEMENTS}

I would like to acknowledge Bob Anderson for his dedication and commitment to excellence in education. 


\section{TABLE OF CONTENTS}

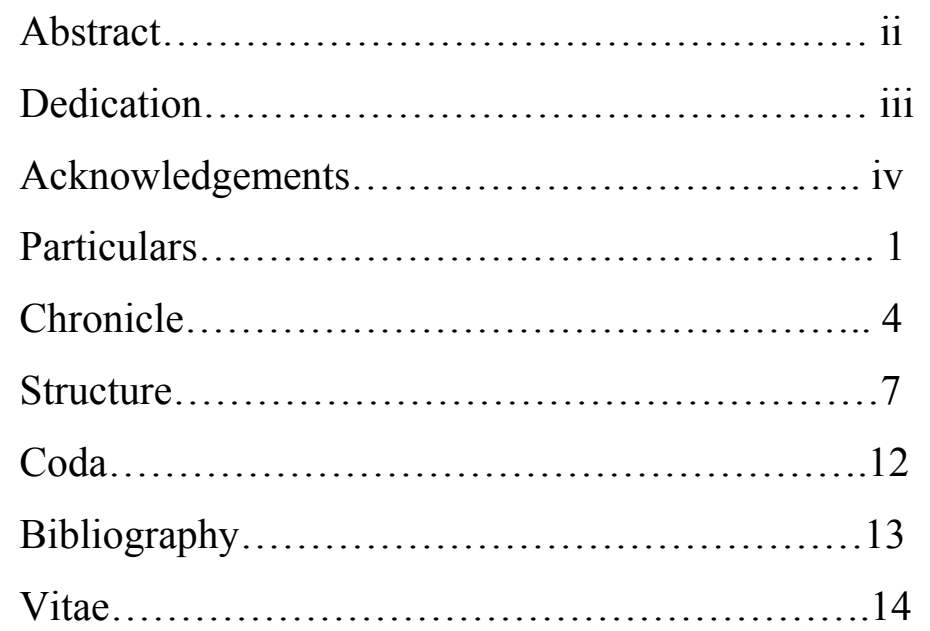




\section{$\underline{\text { Particulars }}$}

"Life Begins well, it begins enclosed, protected, all warm in the bosom of a house." (Bachelard, 7)

In the beginning there was the landscape and a building. There was the natural environment and the artificial. In an endeavor to separate ourselves from the natural world as a means of protection, we sheltered ourselves. We, and that which we held valuable, took refuge from the natural environs.

Architecture, the basic form and structure of a building, can be seen as a metaphoric representation of the human form. I employ the vessel as a metaphor for the human body, the domestic and the sacred. The skin becomes the walls whose function is to protect against the natural world. The four walls bring into being a space; the four walls create a container. These four walls contain while at the same time they protect. The space within is a vessel.

"Of course, thanks to the house, a great many of our memories are housed, and if the house is a bit elaborate, if it has a cellar and a garret, nooks and corridors, our memories have refuges that are all that more clearly delineated." (Bachelard p.8)

The contents of the vessel, or the room, will have multiple meanings. An empty space may have more meaning than one that is cluttered. The value of any given room 
can easily out match that of its market. The room of one's childhood, for example, would have more memories attached to it than could ever fit inside the physical space of its memories. Even though it might have been small, it is bound up in our memories as monumental.

It is the idea of the domestic environment that I am interested in. The idea of home as coupled with the concept of the sacred. Sacred as related to our individual predilection to hold dreams, concepts and even objects in regard with great respect and reverence. It is the idea of the sacred, not a specific element, but only the possibility of the sacred that I find most compelling.

The architectural form is by design protecting that which it contains. I reference the idea of containment and storage by designing vessels that store containers. As a vessel, architecture represents protection and nurture. The vessel that is itself a receptacle for a smaller container relates to the ideas of motherhood and soul. It is the creation of this sacred space that is key to my work.

The idea of the venerated object within space, contained and protected as if in a womb or a relic in a cathedral, is central to my current body of work. First, one must recognize the possibility of the sacred in order to encourage reflection on that which we revere. The seed represents this possibility, and is at the same time the origin of all things physical. This thought, in turn, leads to meditative reflection.

In the buildings I have constructed an inner chamber. Within the inner chamber is a pure white box that contains red clay. This is the same material from which the foundation was constructed. This is the same material employed in the construction of the 
building, the four walls, and the tower. This is the same material that the steps were carved from, and the doors and windows were cut from. The roves were fabricated using the red clay. Nestled within the bed of red clay is the seed.

The seed is representational of origins and beginnings. I shall contend that it was neither the chicken nor the egg but the seed that came first. The seed brings harvest, food for thought if you will. As the room bound up with childhood memories it is the seed that has singular, while at the same time multiple, meaning.

Seeds are symbolic of potential: seeds have the capacity to develop into something in the future. Nestled in the red clay these seeds are nourished by the same material that provides its protection and preservation. The object of fortification is at once the protector and the protected.

It is through the use of architecture as a container or vessel that I choose to address the subject of the human body, the domestic and the sacred. Architecture as a metaphor for the human body and how both function as a vessel is central to my work. I approach the subject of containment and preservation by fashioning vessels that store containers. The walls of the tower rooms function as a protective skin, while the Venus figures represent nurture and protection. The seed, safeguarded in a bed of red clay, represents the sacred and its promise. The fortress protecting the sacred seed makes the seed possible. 


\section{$\underline{\text { Chronicle }}$}

The exhibition at the Mesaros Galleries is made up of two bodies of work.

Architectural sculptures, which includes two subsets; floor pieces and wall niches as well as a wall installation made up of Venus imagery. I will address each body of work in the aforementioned order. It is important to note that as I worked toward my MFA exhibition I began to conceive of my work in the gallery as an installition. I considered the gallery as a whole, and the pieces as parts which make up the whole. I believe that this conceptualization aided in creating a cohesive, visually organized body of work.

The floor pieces in the architectural series are vertical buildings with windows, an occasional door, and peeked roofs. Each of these architectural features is perched on a form referencing the natural environment. For some pieces this environment becomes manifest as a stratified pedestal and for others a tower of meadow and rock juts straight out of the floor reaching upward. These organic forms ground the buildings and give them there own firm location in space.

The architectural forms are reminiscent of early European fortifications (for example: early Moorish castles in Spain). In each piece there is a tower that serves as a container, vessel or room for a box. Inside the box is the relic. Combinations of windows are used to force the audience to move around the piece, jockeying for the best view. Some of the windows are thin slats, which force the viewer into an intimate relationship with the piece. A possible byproduct of the small openings is that it is feasible that one could pass by the piece completely unaware and miss that there is something contained 
within this small space. The interior space therefore becomes a reward for the patient observer, the meticulous viewer and for the curious most of all.

The surface of the pieces in the architectural series is similar to igneous rock. It has the appearance of charred earth. Each piece has two basic components: the organic and the inorganic. This dichotomy is not addressed in the treatment of the surface, for both the landscape and the building are treated with the same glaze. While various dichotomies are explored in the works, the single glaze is intended to unify the pieces into whole works.

Beside the organic vs. inorganic, there is an exterior vs. interior dialogue. The hard, rough, black surface of the geometric, fortified buildings juxtaposed against the soft white interior container and the shiny surface of the bronze seed. Thus a clear line is draw between the protecting and the protected.

The wall niches work on the same principle as the houses in the floor pieces. The niches are composed of two parts: the grounding element and the house. Unlike the floor pieces, the grounding element for the wall niches is an architectural feature rather then a form derived from nature. The cantilever shelf is representational of architectural niche platforms in churches and window niches found in stone castles. These seven pieces were installed in the gallery at varying heights from six to eight feet.

The height of the wall niche installation makes them inaccessible. Residing above the heads of the viewer, these pieces are placed firmly in the role of architectural detail. The houses contain, the same as the floor pieces, white boxes. These however, are inaccessible to the viewer. This is sometimes the nature of architectural detail, as well as 
the sacred.

In the back of the gallery is a grid of Venus figures that hover in front of the wall. These figures are seven inches long, slip cast from a red earthenware body and unglazed. Evidence of their creation can be seen in the vertical seams which run along both sides and over the top of the head of the figures. The holes in the feet and the seams are indicative of a two-part mold process.

From the entrance of the gallery the wall appears as a field framed by the ceiling, floor and two walls on either side. As the viewer approaches the wall, the singular image of the grid breaks down and the individual figures become more delineated. As the viewer approaches the wall, the grid fills their peripheral vision. The gallery slips from view as the field of vision is filled with the wall. The illusion of infinity envelops the viewer. Even as the viewer experiences the individual figures (a personal relationship with the divine) there remains a sense of the divine's infinite nature.

The stark contrast between the unglazed Venus figures and the black surface of the architectural series alludes to a theme of opposites. Previously noted themes include: Nature and synthetic, exterior and interior. It is in this way that the two bodies of work, though appearing striking different in content and approach, unite through the universal code of opposites. It is this relationship between the female figures and their counterparts of fortified architectural vessels that begins a dialogue. This dialogue is about the nature of sacred, not the specifics of sacred. These pieces allow for the beginning of a conversation; a conversation that is ongoing. 


\section{$\underline{\text { Structure }}$}

There are artists and there are ceramic artists. To work in clay is to work with an insidious material, known to lead to obsessive behavior. Clay, as an artistic medium, requires an obstinate character and fortitude. Never the less, the attraction of this material is irresistible for some. Ceramic art can be an unfortunate bedfellow due to its allencompassing nature, including both the abundance of raw material at hand and the plethora of objects created in clay throughout history. It is an unfortunate fact that the art community attaches a stigma to ceramic arts citing its primitive and humble history. As far as pots go, it does seem as though it has all been done before.

This history, humble and primitive though it may be, is what I find most compelling about ceramic arts. It is the humanity of ancient ceramic vessels as the first artistic expression, couched with the connection to the everyday and to ritual, which becomes the mantra of the ceramic artist. They seek a connection to our shared history, the past filled with its primitive ceramic wares. Trained early on as a functional potter my interest was related to the idea of containment. All functional pots are intended to hold, display and contain.

In evaluating my working methods, what became evident was that my interest lay in the physical manipulation of the material. Building containers, or vessels, from slabs proved to be the most direct route from point a to point $b$. The combination of squares, the small within the larger, presented an almost unending list of possibilities. The visceral physicality of ripping and stacking slabs in the production of landscapes or 
pedestals provided a necessary balance of plan and happenstance. The manipulation of the material through coil building, pinching and paddling in the end proved most effective in communicating with the medium.

When the scale of my work increased exponentially, I ran into a pile of technical problems. Planning, on a variety of levels, became incredibly important. Much different than the approach taken at the wheel (which could be described as improvisational), I was faced with structural needs that required consideration. Thus specific structural elements had to be factored in at the beginning of the piece.

Resistance to forethought proved futile. Planning manifested in reformulation of my clay body as well as massive re-conceptualization of internal support structures. The low-fire red earthenware body that I was intent on using needed an additional 30 percent grog to 100 pounds of dry material. The addition of already fired material, in varied sizes, facilitated even drying and firing. Though these additions were in no way helpful with the overall plasticity of the material (in slab form the clay wanted to rip), it was a great benefit to dry strength. This became key when I made the transition from the more standard practice of bisque firing before glazing to dry glazing and once firing. Internal structure became key in supporting larger pieces. When building the pedestals of stacked ripped slabs, it was important to keep the thickness at a minimum by pairing down the width of the ripped slab. In reducing the width of the individual strata it was imperative to support the weight of the walls by an internal cross member. 


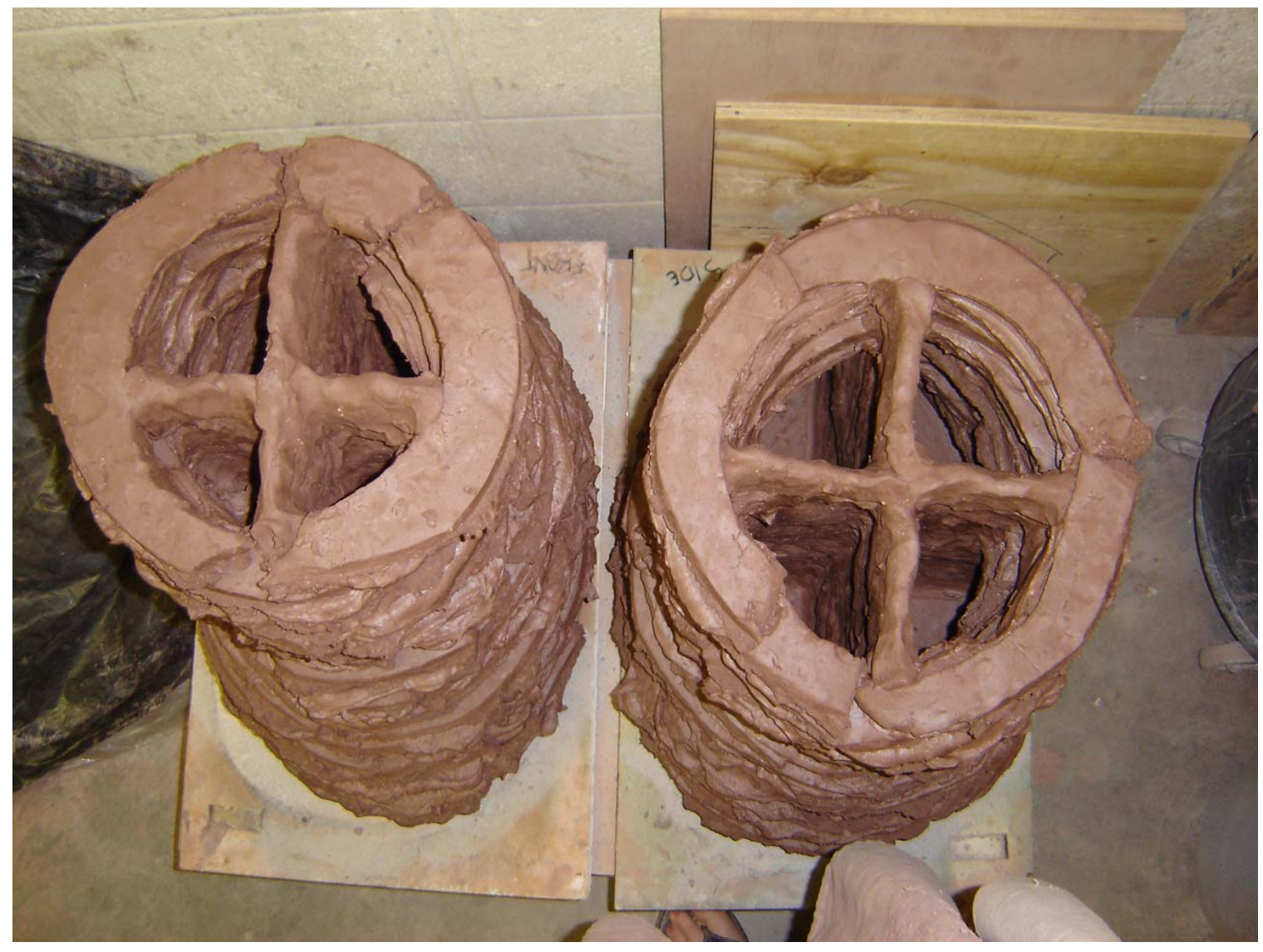

This system of internal support was also necessary in supporting the walls of larger coil built bases. This was necessary to keep the walls from moving as well as to support the slab and tabs on the top of the base. As the pieces grew it became necessary to section the pieces for ease in transport. This sectioning necessitated considerations related to locking mechanisms. I settled on using tabs in the base with cutouts in the bottom of the second piece which would fit over the tabs at the top of the base. I settled on two tabs set at angles to enable ease in installation. 


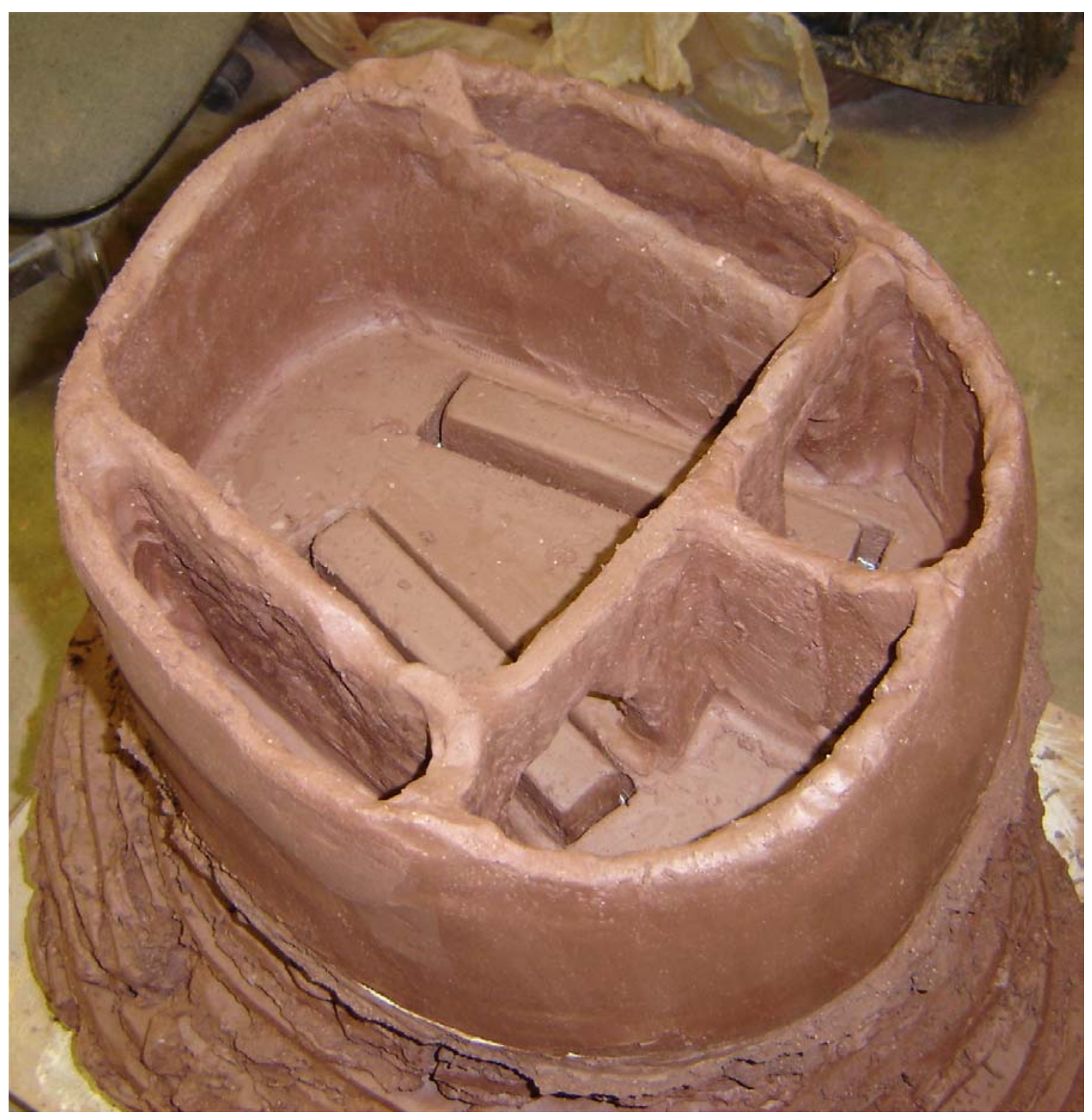

I relied on similar locking mechanisms for the houses. The houses sit inside a box. At the base of the box there is the same tab arrangement to keep the houses firmly in position. I was interested in creating the illusion that the houses were firmly planted in the landscape. This illusion was aided by sinking the footings for the house forms into the landscape. 


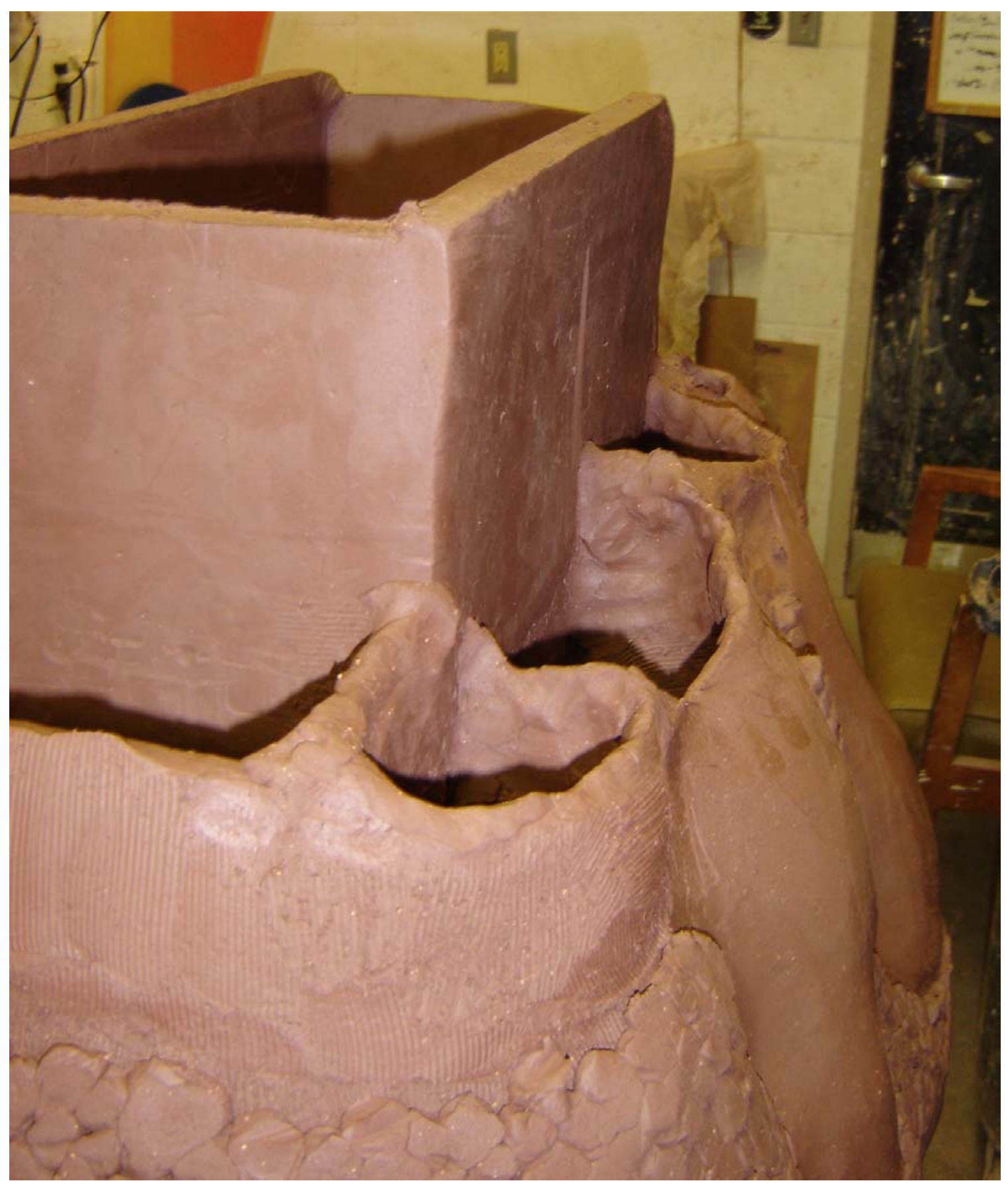

In this image the box form was placed into the landscape before the landscape was completed. This enabled the landscape to grow up around the footprint of the house, reinforcing their relationship. 


\section{Coda}

In my work I employ architecture as a metaphor for the human body. It is the idea of the vessel employed to contain and protect that I am interested in. That which we hold valuable is what we wish to preserve.

It is my intent to address themes of opposites. By combining opposing themes my work strikes a balance by joining ideas related to interior/exterior and natural/synthetic. It is this coupling of seemingly disparate concepts that alludes to universal themes.

It is the seed that gives birth to the potential of the sacred, that which we choose to protect. Whether in a Buddist Stuppa or a Christian Cathedral, our hopes are bound up in the potential of the sacred object. It is through the creation of landscapes that hold buildings, and the buildings which house the sacred (all of which are made from the same material), that I address the sacred nature of everything.

In addressing my MFA exhibition as an installition I created a dialogue in the gallery. The floor pieces were positioned in such a way as to facilitate a conversation with each other as well as with the audience. The wall niches positioned opposite the Venus installition also dialogue. The groupings resonate as they address the concept of housing the sacred. 


\section{Bibliography}

Bachelard, Gaston. 1969. The Poetics of Space. Boston, Massachusettes: Beacon Press.

Norberg-Schultz, Christian. 2000. Architecture: Presence, Language, Place. Milan, Italy: Skira Editore.

Rykwert, Joseph. 1987. On Adam's House in Paradise. Cambridge, Massachusettes: MIT Press. 


\section{VITAE}

\section{EDUCATION}

2006

2002

MFA, Ceramics, West Virginia University, Morgantown, West Virginia. BFA, Cum Laude, Ceramics, Southern Illinois University, Carbondale Illinois.

\section{PROFESSIONAL EXPERIENCE}

2006

2005

2005

2005

2004

2004

2003-2004

2003

2003

2002-2003

1996-2002

1992-1996

1992
Teacher of Record, Spring Term, Non-Major Ceramics, West Virginia University, Morgantown, West Virginia.

Teaching Assistant, Fall Term, Beginning Ceramics, West Virginia University, Morgantown, West Virginia.

Teacher of Record, Summer Term, Non-Major Ceramics, West Virginia University, Morgantown, West Virginia.

Teacher of Record, Spring Term, Non-Major Ceramics, West Virginia University, Morgantown, West Virginia.

Teaching Assistant, Beginning Ceramics, West Virginia University, Morgantown, West Virginia.

Garo Galleries, poster restoration, Morgantown, West Virginia.

Gallery Assistant, Mesaros Galleries, West Virginia University, Morgantown, West Virginia.

Instructor, Intermediate Ceramics, Office of Continuing Education, Southeast State University, Cape Girardeau, Missouri.

Preservation Consultant, Library of Congress Grant, Cairo Pubic Library, Cairo, Illinois.

Preservation Consultant, Illinois State Library Grant, Chester Public Library, Chester Illinois.

Preservation Unit Coordinator, Library Affairs, Southern Illinois

University, Carbondale, Illinois

Conservation Lab Manager, Library Affairs, Southern Illinois University, Carbondale, Illinois.

Instructor, Kid Architecture Summer Program, Southern Illinois University, Carbondale, Illinois.

\section{EXHIBITIONS and PUBLICATIONS}

2006

2006

2005

2005

2005

2004
'Summer Show', Mesaros Gallery, West Virginia University, Morgantown, West Virginia.

MFA Thesis Exhibition, Mesaros Gallery, West Virginia University, Morgantown, West Virginia.

'As You Like It', Mesaros Gallery, West Virginia University, Morgantown, West Virginia.

500 Cups, Lark Books.

'Exchange', Ohio University, Athens, Ohio.

Solo exhibition, Zen Clay, Morgantown, West Virginia. 
'Teachers and Students', Zen Clay Gallery, Morgantown, West Virginia. 'Clay Cup IX', Juror Richard Shaw, University Museum, Southern Illinois University, Carbondale, Illinois.

2002 'Works 2: combined faculty and grad show', Surplus Space, Southern Illinois University, Carbondale, Illinois. BFA Thesis Exhibition, HQ Gallery, Carbondale, Illinois. Rickert-Ziebolt, juried exhibition, School of Art and Design, Southern Illinois Univeristy, Carbondale, Illinois.

1999 Illinois Ozarks Craft Guild, juried exhibition, John A. Logan College, Carterville, Illinois. 